\title{
Editorial: Mega Quakes: Cascading Earthquake Hazards and Compounding Risks
}

\author{
Katsuichiro Goda ${ }^{1 *}$, Tiziana Rossetto ${ }^{2}$, Nobuhito Mori ${ }^{3}$ and Solomon Tesfamariam ${ }^{4}$ \\ 1 University of Bristol, Bristol, United Kingdom, ${ }^{2}$ University College London, London, United Kingdom, ${ }^{3}$ Kyoto University, \\ Kyoto, Japan, ${ }^{4}$ The University of British Columbia, Okanagan Campus, Kelowna, BC, Canada
}

Keywords: earthquakes, tsunamis, hazards, risks, risk management

\section{Editorial on the Research Topic}

Mega Quakes: Cascading Earthquake Hazards and Compounding Risks

\section{OPEN ACCESS}

Edited and Reviewed by: Izuru Takewaki,

Kyoto University, Japan

*Correspondence: Katsuichiro Goda katsu.goda@bristol.ac.uk

Specialty section:

This article was submitted to Earthquake Engineering,

a section of the journal Frontiers in Built Environment

Received: 22 January 2018 Accepted: 02 February 2018 Published: 16 February 2018

Citation:

Goda K, Rossetto T, Mori N and Tesfamariam S (2018) Editorial: Mega

Quakes: Cascading Earthquake Hazards and Compounding Risks.

Front. Built Environ. 4:8. doi: 10.3389/fbuil.2018.00008
Mega quakes pose major threats to modern society, generating casualties and fatalities, disrupting socioeconomic activities, and causing enormous economic loss across the world. Recent major disasters, such as the 2004 Indian Ocean tsunami, the 2011 Tohoku Japan earthquake and tsunami, and the 2015 Gorkha Nepal earthquake, are vivid reminders that complex risk cascades drive most earthquake crises. Examples of cascading chains of geological events are as follows: earthquake rupture generating tsunami; strong shaking triggering large-scale landslide and liquefaction; and mainshock inducing a sequence of damaging aftershocks.

Our society and infrastructures are subjected to multiple types of cascading earthquake hazards; therefore, integrated hazard assessment and risk management strategies are needed for mitigating potential consequences due to multiple concurrent hazards. For effective disaster risk reduction, accurate risk assessments of earthquake-related hazards are the fundamental requirements. Moreover, uncertainty modeling and its impact on hazard prediction and anticipated consequences are essential parts of earthquake risk management decision-making.

The Mega Quakes Research Topic collects the cutting-edge research contributions from 84 leading researchers and professionals around the world, who are actively involved with modeling, assessment, mitigation, and management of earthquake hazards and risks. It contains 19 articles that cover a wide range of cascading earthquake-triggered hazards and risks in various geographical regions, including Cascadia (Pacific Northwest), Indian Ocean, Japan, Mexico, and Nepal.

\section{MEGA QUAKES-DAMAGE OBSERVATIONS AND LESSONS FOR DISASTER RISK REDUCTION}

After each major earthquake disaster, we learn new lessons as to what was not effective, what worked well, and what needs to be improved for future. Observing damage patterns from historical events and analyzing gathered data to create new knowledge and practice for enhanced disaster preparedness and risk reduction are the key to achieve sustainable and resilient urban cities and rural communities.

Along this line, Suppasri et al. present a new analysis of human fatality ratios in the 2011 Tohoku Japan tsunami to overcome the limitations of previous investigations of the fatality ratios for global tsunami disasters. This study identifies that tsunami hazard awareness is the key factor influencing human loss consequences. 
Goda et al. and Parajuli and Kiyono report post-earthquake damage survey results after the 2015 Gorkha earthquake in Nepal. Both studies highlight significant challenges related to mainshock shaking, aftershock risks, and landslides in remote mountainous areas. Sound structural design and construction of reinforced concrete (RC) and masonry (brick and stone) buildings are the key to reduce the earthquake risk in Nepal.

Furthermore, Goda et al. present an earthquake reconnaissance work for the 2016 Kumamoto Japan earthquake sequences. The investigation highlights the complex patterns of earthquake damage and loss due to the major mainshock-aftershock ground shaking sequence, ground deformation, landslide, and liquefaction, affecting a wide range of buildings and infrastructure in Kumamoto.

On the other hand, Daniell et al. investigate the aggregate effects of the secondary hazards (e.g., landslide, liquefaction, tsunami, fire, flooding, and surface rupture) on overall earthquake loss by analyzing various sources of earthquake damage and loss data reported in the literature. Their analysis provides a useful empirical evidence regarding how important to account for cascading hazards and compounding risks in earthquake impact assessment.

\section{ASSESSING HAZARDS AND RISKS DUE TO STRONG GROUND MOTIONS}

Ground shaking is the primary cause of earthquake damage and loss. Assessing seismic hazards and risks accurately is a formidable task because of large uncertainties associated with earthquake rupture processes, seismic wave propagation, nearsurface site effects, and seismic vulnerability of buildings and infrastructure. This is particularly the case for mega quakes, where earthquake rupture is very complex and triggers numerous aftershocks over a prolonged period and buildings are excited by long-duration strong ground motions.

Goda et al. develop an extensive dataset of real mainshockaftershock sequences for Japanese earthquakes. To evaluate the structural damage potential of major aftershocks quantitatively, the study carries out an empirical assessment of peak and residual ductility demands of numerous inelastic systems having different vibration periods, yield strengths, and hysteretic characteristics.

Ghofrani et al. present a recent development of the stochastic finite-fault method for the Cascadia subduction earthquake scenarios in the Pacific Northwest by accounting for uncertainties of the key model parameters, such as stress drop, regional attenuation, and local site effects. The study highlights the challenges that need to be overcome in future studies to obtain more accurate estimates of strong ground motions that might be experienced in the next mega-thrust event in Cascadia.

Tesfamariam and Goda propose a novel seismic performance evaluation framework based on maximum and residual inter-story drift ratios, rather than a single structural response parameter. The developed framework is applied to evaluate the potential impact to non-ductile RC buildings in Victoria, $\mathrm{BC}$, Canada, due to the Cascadia subduction earthquakes.
Furthermore, Tesfamariam and Goda extend the above framework by considering an energy-based damage index as performance indicator. Both new methodologies are particularly suitable for conducting seismic risk analyses of buildings in major subduction environments, where long-period ground motions with repeated major aftershocks are anticipated.

Liu and Hong present a seismic loss estimation study for buildings in Vancouver, BC, Canada by simulating multicomponent ground motion records due to the possible Cascadia subduction events using a stochastic finite-fault method. The study considers structural responses under bidirectional seismic excitations and is a novel extension of the past seismic loss estimation studies for building portfolios.

\section{ASSESSING HAZARDS AND RISKS DUE TO MEGA TSUNAMIS}

Tsunamis that are triggered by mega-thrust subduction earthquakes are highly destructive, and are typical examples of lowprobability high-consequence events. As exemplified during the recent mega tsunami disasters in Indian Ocean, Chile, and Japan, numerous coastal cities and towns around the world might be devastated. Assessing tsunami hazards for future scenarios require proper treatment of uncertain earthquake rupture characteristics. On the other hand, tsunami risk assessments should consider various wave effects, such as non-hydrostatic, local amplification, macro roughness by artificial structures, and debris impact forces, acting on buildings and infrastructure in high-risk coastal areas. To quantify the expected damage or losses due to tsunamis, empirical tsunami fragility and vulnerability functions can be used.

By adopting a novel stochastic tsunami simulation method, Muhammad et al. conduct a probabilistic tsunami hazard analysis in Padang by considering stochastic rupture scenarios in the Mentawai-Sunda subduction zone off Sumatra Island, Indonesia, whereas Mori et al. carry out a probabilistic tsunami hazard assessment for the Pacific coast of Mexico. Both studies generate probabilistic estimates of anticipated tsunami wave profiles at several shallow-water wave recording locations. They highlight strong sensitivity of maximum tsunami height to major earthquake slip locations, thus indicating the importance of accounting for earthquake source rupture uncertainties in future probabilistic tsunami hazard and risk studies.

Nistor et al. present a state-of-the-art research review on debris loads, i.e., solid objects entrained within the inundating flows impacting on structures. This is of critical importance in the design of tsunami-resistant infrastructure. The article summarizes recent advancements in the determination of debris dynamics using an experimental setting, which have enabled to improve the assessment of mechanisms of the debris load as well as of the potential maximum impact loads.

Charvet et al. present a comprehensive review of empirical tsunami fragility modeling, which employs sophisticated statistical methods to develop a correlation between observed tsunami damage and experienced tsunami hazard parameters. The article emphasizes how to assess the quality of current estimations of 
tsunami fragility. The study also introduces the best practice when developing new fragility functions, which is particularly useful for future studies of tsunami fragility modeling.

Latcharote et al. present an intriguing investigation to examine the possible failure mechanisms of six buildings in Onagawa, Miyagi, Japan that were overturned during the 2011 Tohoku tsunami. These failures are caused by combinations of hydrodynamic and buoyancy forces acting on submerged buildings during the tsunami, but also affected by damage to building foundation due to liquefaction prior to the tsunami. The case studies discussed in the article are good exemplars of building collapse due to cascading hazards and compounding risks.

\section{NEW APPROACHES FOR REDUCING CATASTROPHIC IMPACT DUE TO MEGA QUAKES}

To enhance disaster risk preparedness and management against earthquake catastrophes, new multi-hazard approaches are needed by considering the risks due to both primary and secondary hazards. The new assessment methods and tools will improve the current practice of preparing individual hazard-specific maps, which are developed separately and are based on different methods, data, assumptions, and scenarios. Moreover, advances in "high performance computing (HPC)" and "big data" sciences open new avenues to evaluate catastrophic earthquake hazards and risks more rigorously and accurately.

De Risi and Goda develop a novel simulation-based procedure for estimating the likelihood that seismic intensity and tsunami inundation will exceed given hazard levels. The procedure accounts for a common physical rupture process for shaking and tsunami; therefore, cascading multi-hazard impact

Conflict of Interest Statement: The authors declare that the research was conducted in the absence of any commercial or financial relationships that could be construed as a potential conflict of interest.

The handling editor declared a shared affiliation, though no other collaboration, with one of the authors, NM. can be evaluated. The presented work is a first step toward an earthquake-tsunami multi-hazard performance-based engineering framework.

Park et al. develop a new methodology for integrated probabilistic seismic and tsunami hazard analysis (PSTHA), and apply it to the Cascadia subduction zone in the U.S. Pacific Northwest. The method adopts a logic tree approach to quantify the epistemic uncertainties associated with earthquake-tsunami hazard and risk predictions. In future, the proposed PSTHA can be adopted as the basis for a probabilistic multi-hazard damage and loss assessment.

Inspired by the Fukushima Daiichi nuclear power plant crisis aftermath the 2011 Tohoku earthquake and tsunami in Japan, Itoi et al. propose a risk-informed defense-in-depth-based framework. The new method addresses the issues related to treating residual risks and cliff-edge effects in safety-critical facilities more robustly. It provides additional seismic margin by preventing common cause failures.

Hori et al. develop an integrated earthquake simulator (IES) by taking advantages of HPC and a system of automated model construction. The IES enables a seamless simulation of analyzing all processes of earthquake hazard and disaster. The study presents an illustration of quantitative seismic risk assessment for Tokyo Metropolis, which involves more than 100 billion degreeof-freedoms in the simulation. This is a future computational platform of evaluating the earthquake impact to urban cities in an active seismic region.

\section{AUTHOR CONTRIBUTIONS}

KG, TR, NM, and ST handled manuscripts and edited the Research Topic.

Copyright (c) 2018 Goda, Rossetto, Mori and Tesfamariam. This is an open-access article distributed under the terms of the Creative Commons Attribution License (CC BY). The use, distribution or reproduction in other forums is permitted, provided the original author(s) and the copyright owner are credited and that the original publication in this journal is cited, in accordance with accepted academic practice. No use, distribution or reproduction is permitted which does not comply with these terms. 